What kind of careers in science do 15-year-old boys and girls expect for themselves?

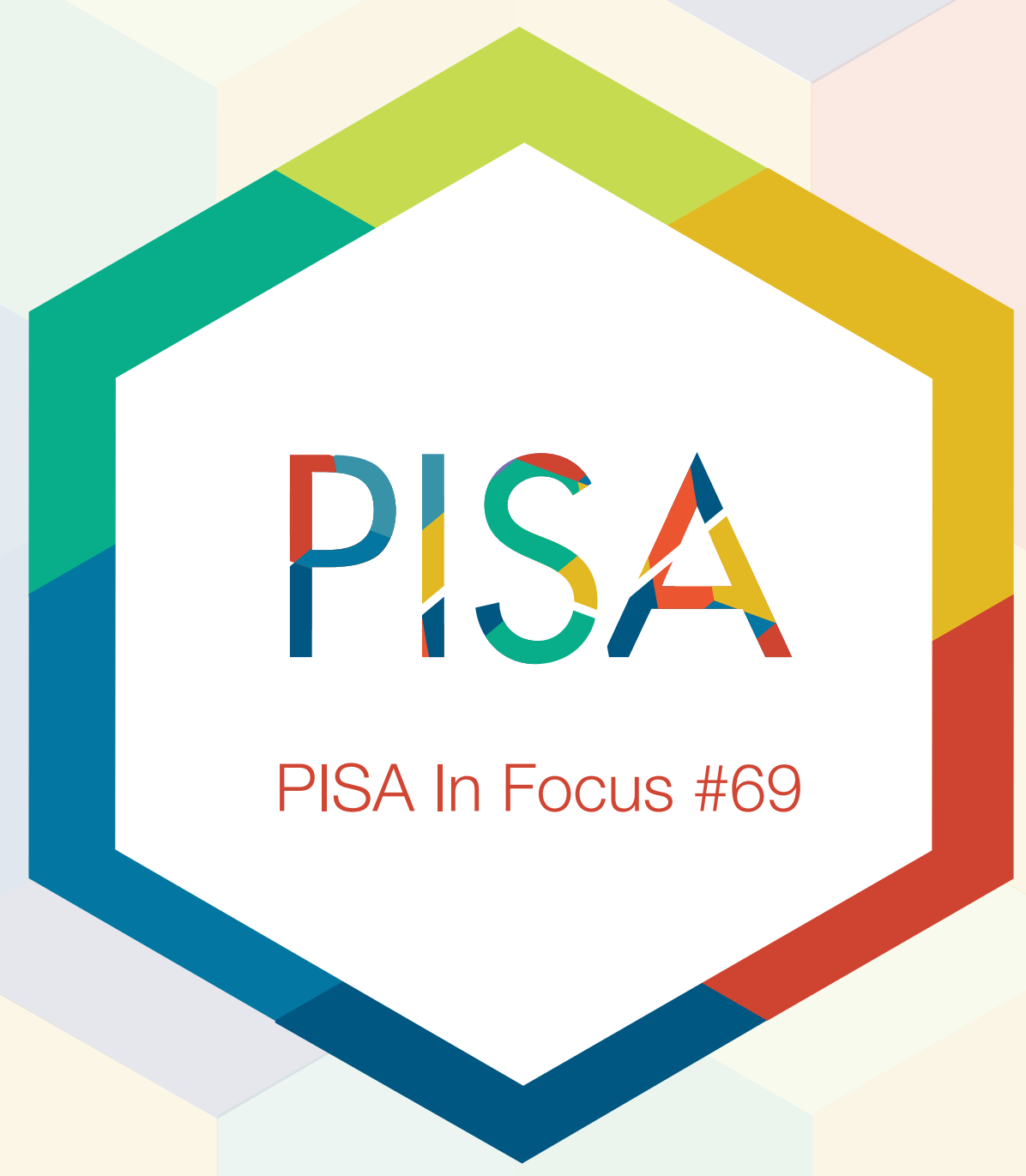




\section{What kind of careers in science do 15-year-old boys and girls expect for themselves?}

- On average across OECD countries, almost one in four students - whether boy or girl - expects to work in an occupation that requires further science training beyond compulsory education.

- Boys are more than twice as likely as girls to expect to work as engineers, scientists or architects; and $4.8 \%$ of boys, but only $0.4 \%$ of girls, expect to work as ICT professionals, on average across OECD countries.

- Girls are almost three times more likely than boys to expect to work as doctors, veterinarians, nurses or other health professionals.

If you recently visited a hospital, chances are that not just the nurses, but also the young doctors that attended to you were women. The rapid increase in the share of women working as doctors shows that even deeply enshrined gender roles can change rapidly. Only a generation ago, in most countries, women represented only a minority among doctors. But not all science-related occupations saw similar progress for women. Very few women have top academic positions in physics, for instance, and the last Nobel prize awarded to a woman in physics was given out in 1963. Meanwhile, new occupations in the emerging information and communication technology industries are often, and overwhelmingly, dominated by men.

Occupational segregation - the fact that women and men work in different occupations, even in closely related fields - is a leading cause of the persistent wage gaps between the genders. Countries that support boys and girls alike in the pursuit of science-related careers may not only reduce pay gaps between men and women, but also ensure that no talent for innovation and growth is wasted - to the benefit of all.

In 2015, PISA asked students about the occupation they expect to be working in when they are 30 years old. Students' responses were later grouped into science-related and non-science-related careers - with the former including science and engineering professionals; health professionals; science technicians and associate professionals; and information and communication technology (ICT) professionals.

\section{Girls and boys are almost equally likely to expect to work in a science-related career.}

On average across OECD countries, almost one in four students (24\%) reported that they expect to work in an occupation that requires further science training beyond compulsory education. Specifically, $8.6 \%$ of students expect to work as professionals who use science and engineering training (e.g. engineer, architect, physicist or astronomer), $11.4 \%$ as health professionals (e.g. medical doctor, nurse, veterinarian, physiotherapist), $2.6 \%$ as ICT professionals (e.g. software developer, applications programmer), and 1.4\% as science-related technicians and associate professionals (e.g. electrical or telecommunications engineering technician). 
Boys and girls are almost equally likely to expect to work in a science-related field, on average across OECD countries: some $25 \%$ of boys, and $24 \%$ of girls expect to do so. But even when the shares of boys and girls who expect a science-related career are balanced, boys and girls have different ideas of what these careers might be.

\section{Expectations of science-related careers among boys and girls \\ OECD average}

Students who expect to work as...

-...science and engineering professionals

1...health professionals

-...information and communication technology (ICT) professionals

n...science-related technicians or associate professionals

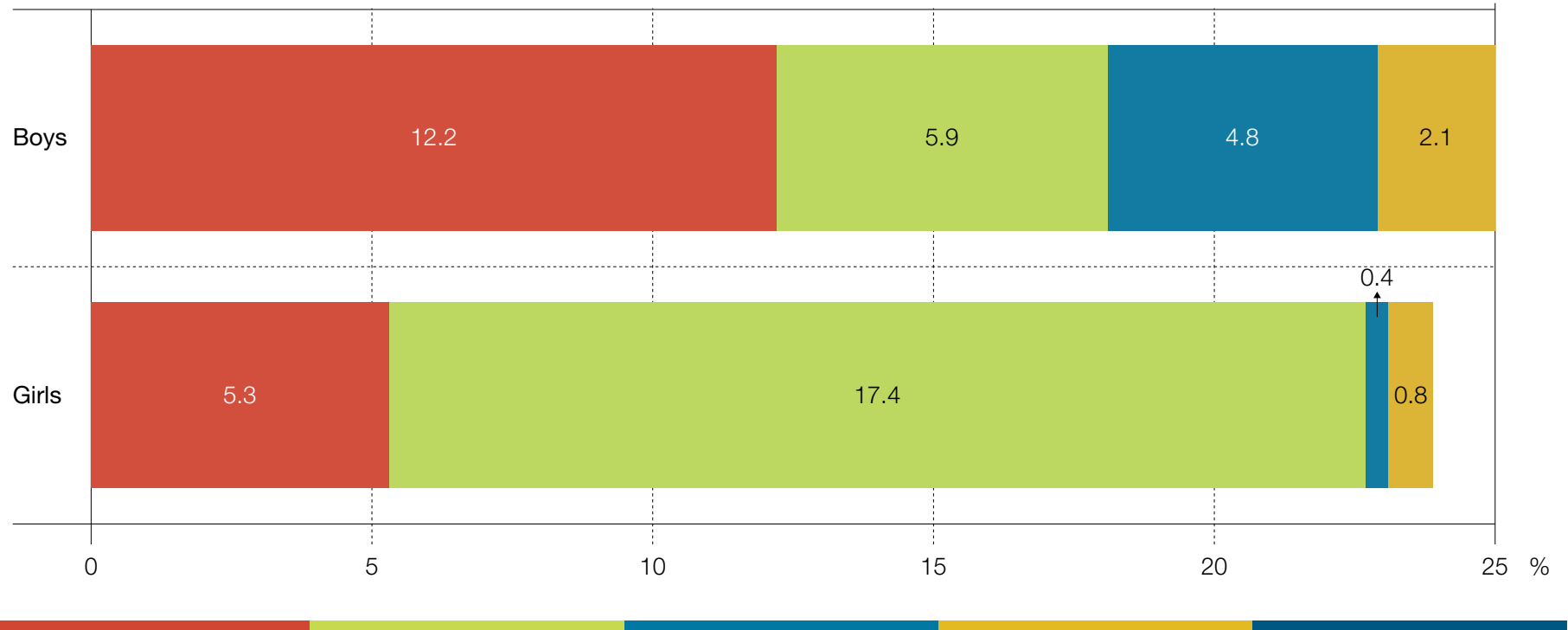

Source: OECD, PISA 2015 Database, Tables I.3.11a-d.

Statlink: http://dx.doi.org/10.1787/888933432311

But boys and girls have different interests and different ideas of what their science careers might be.

Girls are three times more likely than boys to see themselves as doctors, veterinarians or nurses. While a career as medical doctor is a popular choice for boys and girls alike, other health-related careers are rarely considered by boys when asked about their expectations for future work, but are among girls' most frequent choices. These include careers as dentists, pharmacists, physiotherapists, dieticians, nurses, midwives and veterinarians.

Meanwhile, boys see themselves as becoming ICT professionals, scientists or engineers more than girls do. Many girls might see themselves as architects and designers, but far fewer girls envision themselves as engineers or software developers. On average across OECD countries, only $0.4 \%$ of girls, but $4.8 \%$ of boys, expect to work as ICT professionals.

While PISA data reveal 15-year-olds' expectations only - which may well change before crucial career choices are made - the difference between boys' and girls' expectations at age 15 closely matches recent enrolment patterns in tertiary bachelor's degree programmes. In 2013, and on average across OECD countries, women accounted for $78 \%$ of new entrants into health and welfare programmes, but for only $30 \%$ of new entrants into science and engineering programmes. 


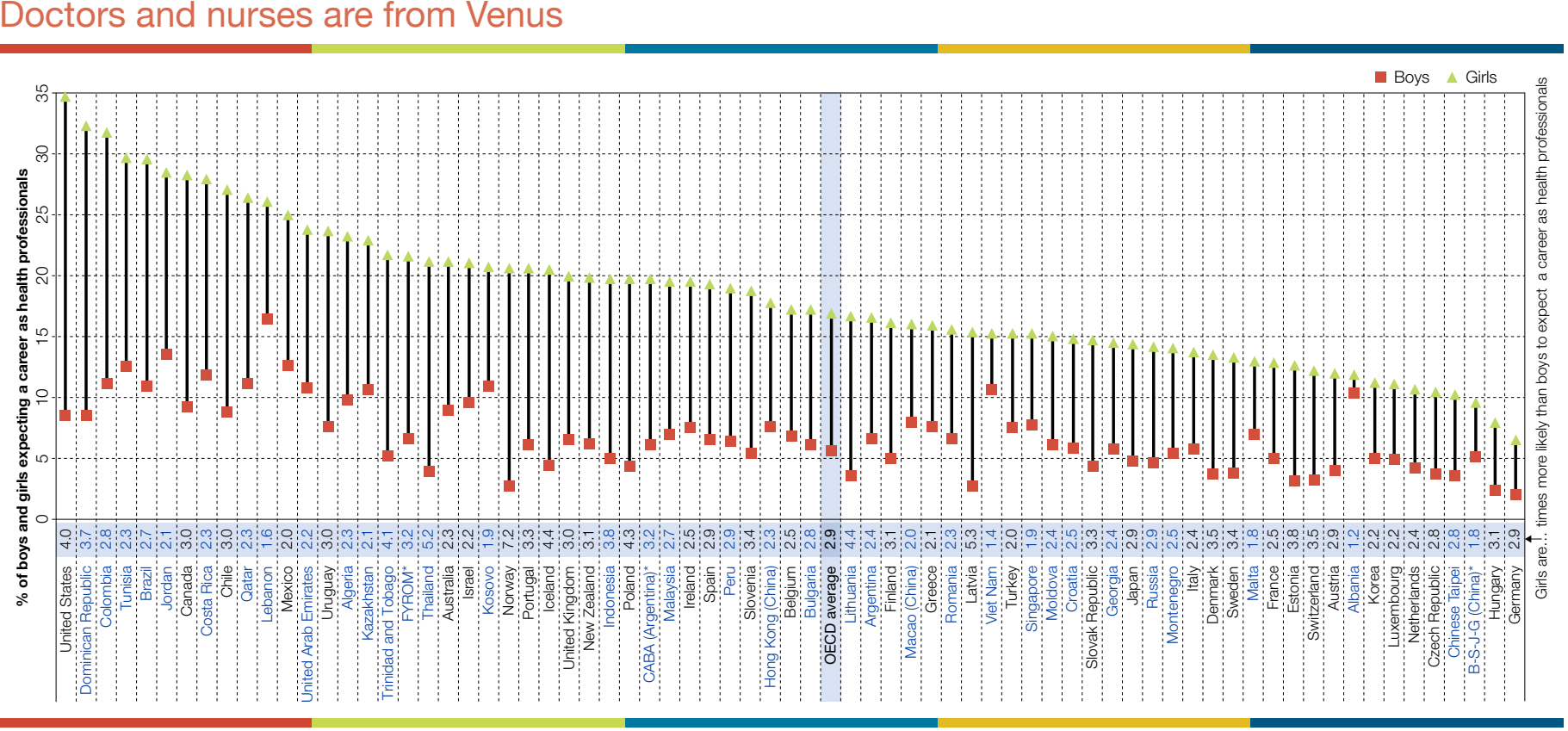

${ }^{*}$ B-S-J-G (China) refers to the four PISA-participating municipalities/provinces in China: Beijing, Shanghai, Jiangsu and Guangdong; CABA refers to Ciudad Autónoma de Buenos Aires, Argentina; FYROM refers to the Former Yugoslav Republic of Macedonia.

Note: The increased likelihood (relative risk) of girls expecting a career as health professionals is indicated next to the country/economy name; "n.s." indicates a relative risk that is not significantly different from 1 (equal likelihood).

Countries and economies are ranked in descending order of the percentage of girls expecting a career as health professionals.

Source: OECD, PISA 2015 Database, Tables I.3.11b.

Statlink: http://dx.doi.org/10.1787/888933433183

Engineers and scientists are from Mars (for now)

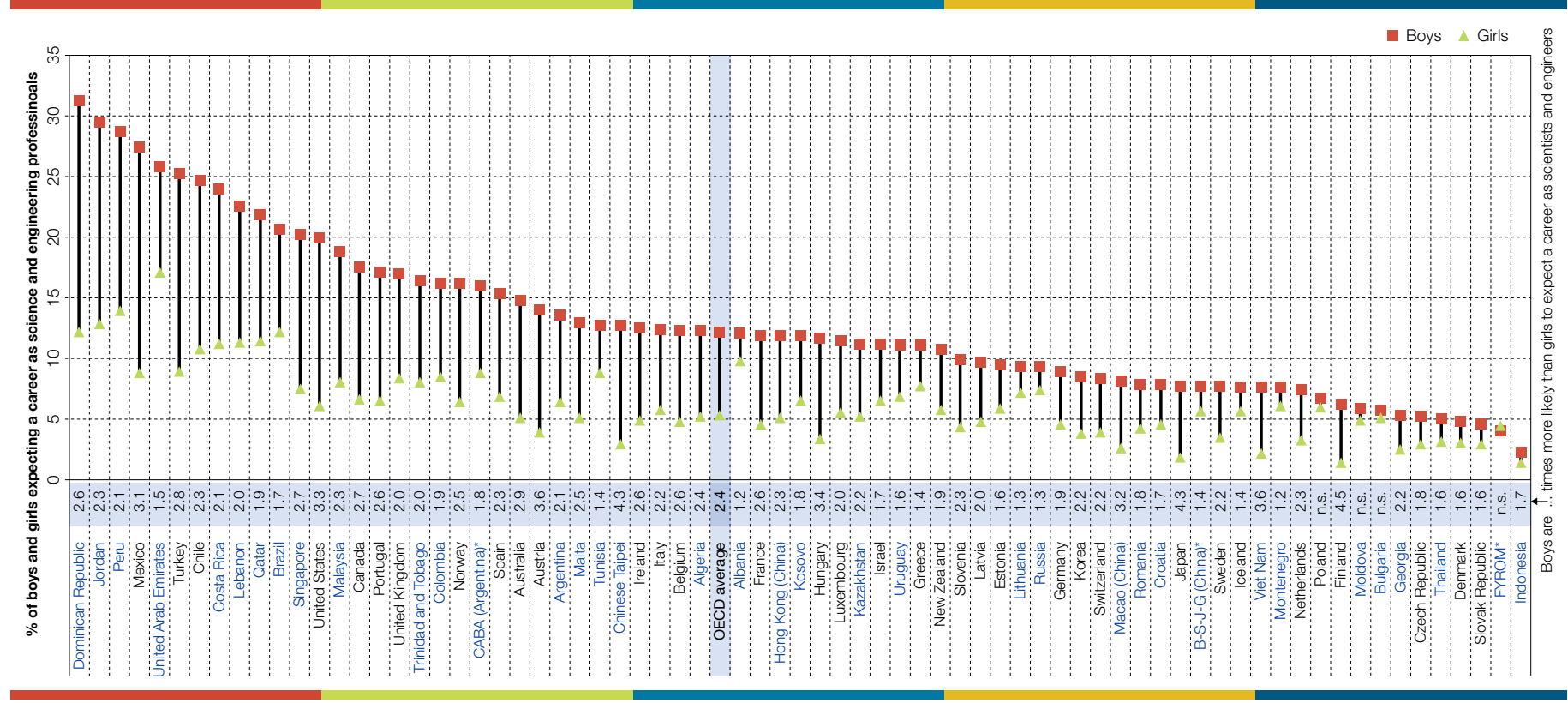

${ }^{\star}$ B-S-J-G (China) refers to the four PISA-participating municipalities/provinces in China: Beijing, Shanghai, Jiangsu and Guangdong; CABA refers to Ciudad Autónoma de Buenos Aires, Argentina; FYROM refers to the Former Yugoslav Republic of Macedonia.

Note: The increased likelihood (relative risk) of boys expecting a career as science and enginnering professionals is indicated next to the country/economy name; "n.s." indicates a relative risk that is not significantly different from 1 (equal likelihood).

Countries and economies are ranked in descending order of the percentage of boys expecting a career as science and engineering professionals.

Source: OECD, PISA 2015 Database, Tables I.3.11a.

Statlink: http://dx.doi.org/10.1787/888933433183 
Particularly large disparities between boys' and girls' expectations for their future are observed in some countries. In Norway, for example, $29 \%$ of boys and $28 \%$ of girls expect a career in a science-related occupation; but there are seven times more girls than boys (21\% compared to $3 \%$ ) who expect to work as doctors, nurses or other health professionals. In Finland, boys are more than four times more likely than girls to expect a career as an engineer, scientist or architect (6.1\% compared to 1.4\%); but girls are more than three times more likely than boys to expect a career as a health professional (16\% compared to 5\%).

To some extent, these differences in expectations reflect the different interests of boys and girls. PISA data show that boys are more interested than girls in science, in general, and in topics related to physics and chemistry, in particular, while girls tend to be more interested in health-related topics. But expectations of science-related careers also often differ among boys and girls who are equally interested in science, and who are equally capable of performing at high levels in PISA. In Germany, Hungary and Sweden, for instance, boys who score at or above Level 5 in science (top-performing boys) are significantly more likely than top-performing girls to expect a career requiring further training in science. This echoes findings from other studies in which many students report enjoying science, but do not perceive science as being something for them.

\section{The bottom line}

Influenced by their family and by popular culture, girls often think of scientists as men in lab coats, see computer science as a "masculine" field, and think that success in science is due to brilliance - which they often find difficult to attribute to themselves - rather than to hard work. Such stereotypes may have some truth to them, but they often discourage young women who are capable and interested in science from envisaging a number of careers in science, technology or engineering.

Schools can counter these stereotypes, and help students cultivate a more inclusive view of science, through better career information. Students should have access to information that is accurate, credible and avoids unrealistic or exaggerated portrayals of career options. Employers and educators in perceived "masculine" or "feminine" fields can also help eliminate existing stereotypes, such as by promoting awareness that computer sciences ("masculine" and "nerdy") help solve health problems ("feminine" and "caring"), or by reaching out and establishing direct contact with students and schools. And teachers can play an important role in cultivating boys' and girls' interests in a diverse range of science topics. 


\section{For more information}

Contact: Francesco Avvisati (francesco.avvisati@oecd.org)

See: OECD (2016), PISA 2015 Results (Volume l): Excellence and Equity in Education, PISA, OECD Publishing, Paris, http://dx.doi.org/10.1787/9789264266490-en.

\section{Visit}

www.oecd.org/pisa

www.oecd.org/pisa/infocus

Adult Skills in Focus

Education Indicators in Focus

Teaching in Focus

Discover PISA 2015 results by country: www.compareyourcountry.org/pisa

Coming next month What do we know about teachers in high-performing countries?

This paper is published under the responsibility of the Secretary-General of the OECD. The opinions expressed and the arguments employed herein do not necessarily reflect the official views of OECD member countries.

This document and any map included herein are without prejudice to the status of or sovereignty over any territory, to the delimitation of international frontiers and boundaries and to the name of any territory, city or area.

The statistical data for Israel are supplied by and under the responsibility of the relevant Israeli authorities. The use of such data by the OECD is without prejudice to the status of the Golan Heights, East Jerusalem and Israeli settlements in the West Bank under the terms of international law

This work is available under the Creative Commons Attribution-NonCommercial-ShareAlike 3.0 IGO (CC BY-NC-SA 3.0 IGO). For specific information regarding the scope and terms of the licence as well as possible commercial use of this work or the use of PISA data please consult Terms and Conditions on www.oecd.org. 